The relationship between attachment styles and alexithymia: Mediating role of self-regulation

Besharat, Mohammad Ali $\$
Department of Psychology, University of Tehran,Iran (besharat@ut.ac.ir)

Salimian Rizi, Mohammad Mehdi

Department of Psychology, University of Tehran, Iran (mm.salimian@gmail.com)

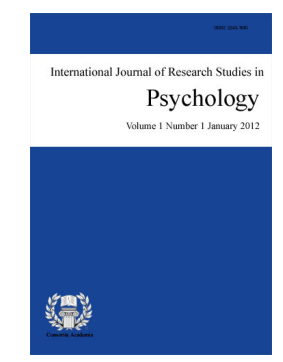

ISSN: $2243-7681$ Online ISSN: 2243-769X

OPEN ACCESS

\title{
Abstract
}

The present study examined mediating role of self-regulation on the relationship between secure, avoidant, and ambivalent attachment styles with alexithymia in a sample of undergraduate students consisted of 546 volunteers (259 males, 287 females). Participants completed Adult Attachment Inventory, Toronto Alexithymia Scale, and the Self-Regulation Inventory. Secure attachment style showed a significant negative association with alexithymia, while avoidant and ambivalent attachment styles showed significant positive associations with alexithymia. Analysis of the data revealed that the relationship between attachment styles and alexithymia was mediated by self-regulation. Secure attachment style as the main effective factor in development of impressive emotion regulation skills provides well identification, expression and better exchange of emotions in social and emotional interactions by reinforcement of self-regulation. In contrast, insecure attachment styles deprive potential developmental opportunities for learning emotion regulation skills within the frame of mother-child and child-environment relations and diminish ability of emotional identification, expression and interactions.

Keywords: attachment; self-regulation; emotion regulation; alexithymia 


\section{The relationship between attachment styles and alexithymia: Mediating role of self-regulation}

\section{Introduction}

The role of childhood experiences in shaping adult interpersonal relationships, healthy behaviors and mental health has been considered and confirmed in many attachment studies. Attachment styles are internal working models that determine behavioral responses to separation and reunion to attachment figures. These styles are often formed based on mother(caregiver)-child experiences, are relatively stable during all life stages, and influence social interactions (Bowlby, 1988). Attachment studies have confirmed the influence of early experiences on emerging mental representations of self and others and examined the way internal working models of attachment effects emotion regulation strategies and later relationships (Dewitte, Houwer, Goubert, \& Buysse, 2010). These mental representations affect perceptions of self and others (e.g., Bartholomew \& Horowitz, 1991).

Studies on attachment styles in childhood show that sensitivity and responsiveness of primary caregiver to child emotions is the main determinant of learning emotional distress regulation strategies and relationship with others (e.g., Bowlby, 1969; Roque \& Veríssimo, 2011). Evidence shows that infants have sensitivity and bias to external signs such as caregiver's facial and vocal signs after the age of three months. These signs play an important role in training emotional distress regulation during infancy (e.g., Vallotton \& Ayoub, 2011). Secure children receive efficient and coherent responses from primary caregivers and learn that appropriate emotional expressions have positive outcomes. Inadequate care leads to the behavior patterns of insecure attachment and prevents development of effective emotion regulation skills.

Across the previous life stages attachment, adult attachment refers to a sustainable tendency for effort to maintain proximity and contact with one or more specific individuals who can provide mental resources of safety and security both mentally and physically. Internal working models of attachment regulate the sustainable tendency that is cognitive-affective-motivational schemata emerging from interpersonal experiences (Bartholomew \& Horowitz, 1991).

Research on adolescents and adults shows that individuals with secure attachment style report lower levels of negative emotions and establish strong relationships with others who can provide them with support when emotionally distressed; while, individuals with insecure attachment style in comparison with secure ones, experience lower levels of positive emotions and show inability to manage stress, anxiety, depression and other negative emotions (Morley \& Moran, 2011). These inabilities mainly manifest in deficiencies of understanding, identifying and expressing emotions.

One known emotional deficiency syndrome is alexithymia, which is a disturbance in affective and cognitive functions, associated with inability to convert affective arousal of experiences into feelings and fantasies that are symbols of emotions. Alexithymia is characterized by continuous describing physical signs instead of describing emotions, thoughts, and speech related to the objective external events and the poverty of imaginative mental life (Sifneos, 2000). Individuals with alexithymia have trouble in recognition, expression, processing and regulation of emotions. Alexithymia is generally considered as a defect in emotion regulation (e.g., Kreitler, 2002).

Emotion regulation is a complicated process involving interactions between neurophysiological, motor-expressive and cognitive-experiential systems of emotion. Therefore, alexithymia appears in different forms such as inability to conceptualize emotions, inability to differentiate emotions, inability to conscious experience of emotions, and inability to describe stress which is transformed automatically to physical dysfunctions (Frawley \& Smith, 2001). Childhood experiences with caregivers who do not show and express 
The relationship between attachment styles and alexithymia: Mediating role of self-regulation

their emotions or do not recognize children's developing emotions and do not deal well with their emotions can have a profound effect on the regulation of emotion in later life stages (Roque \& Veríssimo, 2011). What we know about our emotions and the ability to recognize, describe and regulate them is much influenced by early interactions with the caregiver. Accordingly, it can be assumed that alexithymia is probably related to attachment style.

Studies in the field of attachment show that early caregiver's sensitivity and responsiveness to child's emotions is a fundamental determinant of the regulation of distressing emotions and relationships with others (Bowlby, 1969; Hershenberg, Davila, Yoneda, Starr, Miller et al., 2011). From the age of 3 months, infants are sensitive to perceive the external cues such as caregiver's facial and vocal responses and these cues play important role on the regulation of emotions (Gergely \& Watson, 1996). Lowe and colleagues (2012) found that mothers who have higher responsiveness (i.e., used more contingent responding behaviours, as one of the main attachment components) have infants who show better emotional regulation. In contrast, mothers who use attention seeking behaviours (i.e., behaviours considered to demonstrate less maternal responsiveness) have infants who display less optimal emotional regulation. Consistent with this, several studies showed that there is an association between attachment styles and alexithymia (e.g., Besharat, 2010; Thorberg, Young, Sullivan, Lyvers, Connor et al., 2010). Alexithymia is also associated with parental attitudes (Karukivi, Joukamaa, Hautala, Kaleva, Haapasalo-Pesu et al., 2011) and parental bonding (e.g., Thorberg et al., 2010).

The main question of this study is whether the relationship between attachment styles and alexithymia is a simple direct one or is mediated by other variables such as self-regulation. Therefore, the aim of this study was to examine the mediating role of self-regulation on the relationship between attachment styles and alexithymia. This is important, first because attachment styles influence formation and development of self-regulation capabilities from the childhood (Bowlby, 1969, 1988). Second, the disruption in self-regulation will result in defect and failure in identification and expression of emotions (e.g., Kreitler, 2002).

It has been difficult to achieve consensus on a single definition of self-regulation. Self-regulation is a multidimensional construct including cognitive, motivational-affective, social and physiological processes that affect active control of goal directed actions (Calkins \& Howse, 2004). Functions of self-regulating are employed in the frame of multi-aspect active control processing system, which include initiating, modifying, continuing and coordinating actions of self-regulation (e.g., Dorris, 2009). This system is responsible for execution, attention, inhibition, activation and suppression of inappropriate responses as well as inception and continuity of necessary responses (e.g., Hanif, Ferrey, Frischen, Pozzobon, Eastwood et al., 2012).

From a neural perspective, self-regulation refers to a set of mechanisms underlying the ability to monitor and modulate cognitions, emotions and behaviors (Lewis \& Todd, 2007). Research on brain self-regulation (e.g., Cole, Martin, \& Dennis, 2004) revealed that psychological functions of self-regulation emerge from the cognitive, emotional, and action functions of the brain. Several biological processes including cortical and subcortical systems are involved in neural self-regulation (see Lewis \& Todd, 2007 for a review). Moreover, research demonstrated neural bases both in attachment styles (e.g., Gillath, Canterberry, \& Collins, 2012) and alexithymia (e.g., Bermond, Vorst, \& Moormann, 2006). Results of the present study might shed light on the complex nature of self-regulation. This can be considered as the third reason for the present study. Current study attempted to examine the relationship among attachment styles, self-regulation, and alexithymia. It was hypothesized that the relationship between attachment styles and alexithymia is mediated by self-regulation.

\section{Method}

\subsection{Participants and procedure}

A sample of 560 male and female undergraduate students from the University of Tehran participated in this study, voluntarily. Recruitment conditions were being at undergraduate level and having no medical or 
psychiatric illness requiring medication at the time of study. Participants were asked to take part in a "study on personality and behavior" via announcements made by relevant lectures in classrooms. Questionnaires were completed in classes consisting of 20-30 students in the presence of the researchers who gave a brief description of the materials and answered questions. Fourteen subjects were excluded from statistical analysis because of incomplete responses to the scales, thus the final study sample reduced to 546 participants ( 259 males; $M_{\text {age }}=$ 23.3 years, $S D=2.7$, age range: $18-29$ years; 287 females; $M_{\text {age }}=22.1$ years, $\mathrm{SD}=2.5$, age range: $18-27$ years). All participants were asked to complete Adult Attachment Inventory (AAI), Toronto Alexithymia Scale-20 (TAS-20), and Short version of the Self-Regulation Inventory (SRI-S). The order of the questionnaires was counterbalanced across participants.

\subsection{Measures}

Adult Attachment Inventory (AAI) - This scale has 21 questions which was derived from the Attachment Style Questionnaire (Hazan \& Shaver, 1987), the Relationship Questionnaire (Bartholomew \& Horowitz, 1991), and the Attachment History Questionnaire (Crowell, Fraley, \& Shaver, 1999) and validated for the purpose of measuring attachment styles in Iranian populations (Besharat, 2005). Items consisted of statements that had previously proved useful in assessing 3 styles of attachment including secure attachment (7 items), avoidant attachment (7 items), and anxious/ambivalent attachment (7 items). Participants respond to the items using a five-point Likert-type scale ranging from 1 (very little) to 5 (very much).

Cronbach's coefficients alpha for secure, avoidant and ambivalent attachment style subscales in a sample of 1480 participants (860 females, 620 males) were $.85, .84$, and .85 for all subjects; $.86, .83$, and .84 , for women; and $.84, .85$, and .86 for men, respectively. These are indicative of adequate internal consistency of the scale. Correlation coefficients to assess test-retest reliability in a sample of 300 participants were calculated in two occasions over a 4-wk. period. They were $.87, .83$, and .84 for secure, avoidant and ambivalent attachment styles, respectively. All correlation coefficients were significant at $p<.001$. These coefficients are indicative of adequate test-retest reliability of the AAI. Construct validity of the AAI was confirmed by factor analysis that identified three factors named secure, avoidant and ambivalent attachment styles. These results indicate sufficient reliability and validity of the Adult Attachment Inventory.

The Farsi version of the Toronto Alexithymia Scale-20 (FTAS-20) - The FTAS-20 is a Farsi version of The Toronto Alexithymia Scale (TAS-20; Bagby, Parker, \& Taylor, 1994) validated for Iranian populations (Besharat, 2007). The FTAS is a 20-item self-report questionnaire and measures three aspects of alexithymia including difficulty in identifying and describing feelings and concrete thinking. Each item is rated on a five-point Likert scale ranging from 1 (strongly disagree) to 5 (strongly agree). The TAS-20 has demonstrated good psychometric properties (e.g., Thorberg et al., 2010). Adequate psychometric properties of the scale have reported for Iranian populations (Besharat, 2007).

Short version of the Self-Regulation Inventory (SRI-S)- The SRI-S (Ibáñez, Ruipérez, Moya, Marqués, \& Ortet, 2005) is a 25 -item inventory and measures self-regulation in five subscales including positive actions, controllability, expression of feelings and needs, assertiveness and well-being seeking. Each item is rated on a five-point Likert scale anchored by 1 (very little) to 5 (vary much). Higher scores in this scale indicate higher levels of self-regulation and skills associated with this variable. Adequate psychometric properties of the scale have been reported for the English (Marques, Ibanez, Ruiperez, Moya, \& Ortet, 2005) and the Farsi (Besharat, 2011) versions.

\section{Results}

Means and standard deviations for all scales are presented for males, females, and the total sample in Table 1. A preliminary analysis involved examining all scales to determine if there were gender differences. A multivariate analysis of variance (MANOVA) was performed on measures of attachment styles, alexithymia, and 
The relationship between attachment styles and alexithymia: Mediating role of self-regulation

self-regulation as a function of the categorical variable of gender. There was no significant effect for gender (Wilks' Lambda $=.99, \mathrm{~F}_{(540,5)}=.62$, Eta Squared $\left.=.007\right)$. Therefore, subsequent analyses were collapsed across gender. Zero order correlations between attachment styles, alexithymia, and self-regulation are presented in Table 2. As expected, significant correlations were obtained between attachment styles, alexithymia, and self-regulation.

Table 1

Mean scores and standard deviations on each scale of the attachment, alexithymia, and self-regulation variables for males, females, and the total sample

\begin{tabular}{lcccccc}
\hline \multirow{2}{*}{ Variable/Scale } & \multicolumn{2}{c}{ Males } & \multicolumn{2}{c}{ Females } & \multicolumn{2}{c}{ Total } \\
\cline { 2 - 7 } & M & SD & M & SD & M & SD \\
\hline Secure attachment style & 21.32 & 8.54 & 20.87 & 9.12 & 21.08 & 8.83 \\
Avoidant attachment style & 15.32 & 7.44 & 15.99 & 7.86 & 15.67 & 7.65 \\
Ambivalent attachment style & 12.23 & 6.73 & 12.64 & 5.86 & 12.45 & 6.30 \\
Alexithymia & 44.29 & 14.14 & 44.83 & 11.26 & 44.57 & 12.70 \\
Self-regulation & 95.06 & 19.90 & 94.71 & 18.42 & 94.88 & 19.12 \\
\hline
\end{tabular}

Table 2

Zero order correlations between attachment styles, alexithymia, and self-regulation for the total sample

\begin{tabular}{lllll}
\hline Variable & 1 & 2 & 3 & 4 \\
\hline 1. Secure attachment style & 1 & & & \\
2. Avoidant attachment style & -.54 & & & \\
3. Ambivalent attachment style & -.65 & .68 & & \\
4. Alexithymia & -.49 & .40 & .50 & -.57 \\
5. Self-regulation & .37 & -.33 & -.44 & \\
\hline
\end{tabular}

Note. All $p$ values $<.001$

To examine the mediating role of self-regulation, hierarchical multiple regression analyses were conducted with alexithymia as the dependent variable and each of the attachment styles as independent variable in first step, then self-regulation entered to the regression equation as the mediating variable. The results are presented in Table 3 .

Table 3

Summary of regression analyses for mediating role of self-regulation between attachment styles and alexithymia

\begin{tabular}{|c|c|c|c|c|c|c|c|}
\hline & & $\mathrm{R}^{2}$ & $\Delta \mathrm{R}^{2}$ & $\mathrm{~B}$ & SE B & $\beta$ & $\mathrm{t}$ \\
\hline \multirow[t]{5}{*}{1.} & Step 1 & .24 & & & & & \\
\hline & Secure attachment style & & & -1.55 & .118 & -.490 & -13.21 \\
\hline & Step 2 & .42 & .17 & & & & \\
\hline & Secure attachment style & & & -1.03 & .111 & -.327 & -9.27 \\
\hline & Self-regulation & & & -.30 & .023 & -.449 & -12.71 \\
\hline \multirow[t]{5}{*}{2.} & Step 1 & .16 & & & & & \\
\hline & Avoidant attachment style & & & 1.15 & .112 & .406 & 10.35 \\
\hline & Step 2 & .38 & .21 & & & & \\
\hline & Avoidant attachment style & & & .695 & .102 & .244 & 6.80 \\
\hline & Self-regulation & & & -.325 & .024 & -.489 & -13.62 \\
\hline \multirow[t]{5}{*}{3.} & Step 1 & .24 & & & & & \\
\hline & Ambivalent attachment style & & & 1.73 & .133 & .489 & 13.06 \\
\hline & Step 2 & .40 & .16 & & & & \\
\hline & Ambivalent attachment style & & & 1.05 & .131 & .297 & 8.00 \\
\hline & Self-regulation & & & -.292 & .025 & -.440 & -11.86 \\
\hline
\end{tabular}

Note. All $p$ values $<.001$

For secure attachment style, absolute value of the standardized coefficient ( $($ ) decreased from 0.49 to 0.32. The Sobel test showed that this difference is significant $(t=-12.71, p<.001)$ while secure attachment style also remained significant ( $t=-9.27, p<.001$; see Fig. 1$)$. 


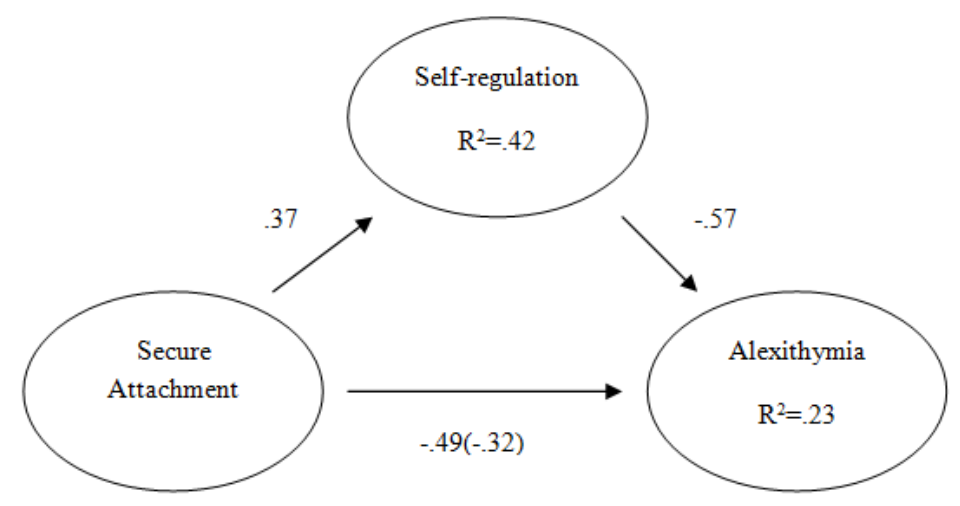

Note. All $p$ values $<.001$

Figure 1. Mediating role of self-regulation between secure attachment style and alexithymia

Results repeated for insecure attachment styles and verified the partial mediating role of self-regulation between both avoidant and ambivalent attachment styles and alexithymia (see Fig. 2 and 3).

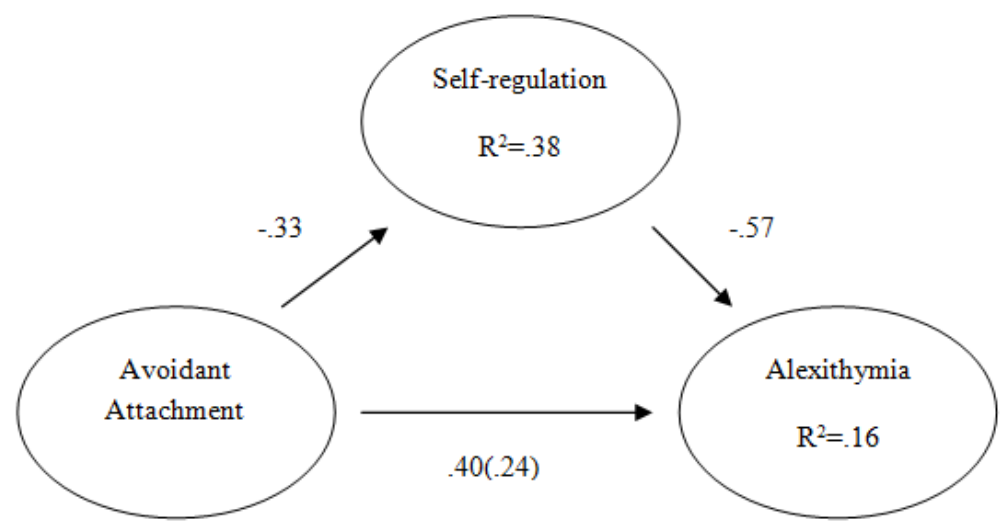

Note. All $p$ values $<.001$

Figure 2. Mediating role of self-regulation between avoidant attachment style and alexithymia

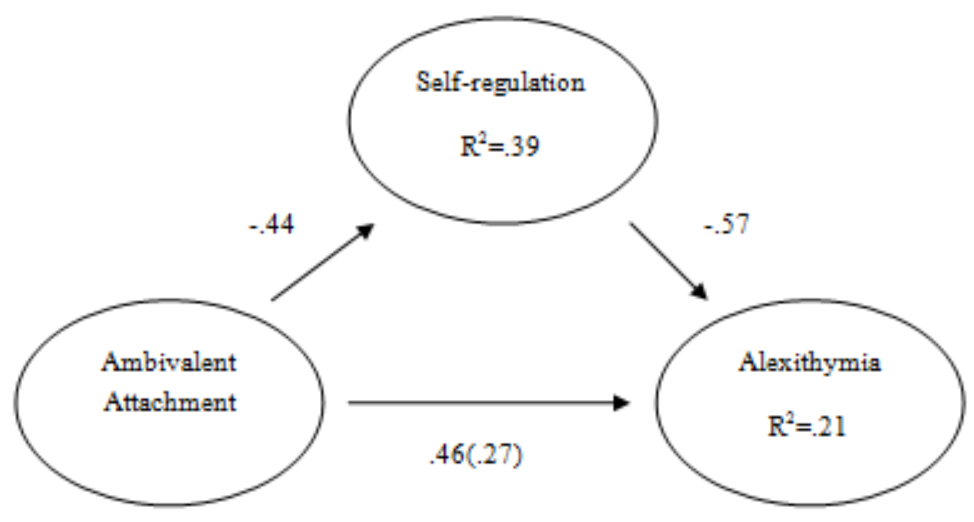

Note. All $p$ values $<.001$

Figure 3. Mediating role of self-regulation between ambivalent attachment style and alexithymia

\section{Results and Discussions}

This study examined the mediating role of self-regulation on the relationship between attachment styles and 
alexithymia in a sample of undergraduate students. Results of the present study showed that secure attachment style had significant negative correlation with alexithymia, while avoidant and ambivalent attachment styles had positive significant correlations with alexithymia. These results are consistent with previous findings (e.g., Besharat, 2010; Wearden, Lamberton, Crook, \& Walsh, 2005). Emotion regulation strategies are developed and learned within the context of mother (caregiver)-child relationships. Studies on attachment styles in childhood show that sensitivity and responsiveness of primary caregiver to child's emotions is the main determinant of learning emotional distress regulation strategies (e.g., Bowlby, 1969; Roque \& Veríssimo, 2011). According to these findings, childhood emotional experiences have a determinant role in emotional functioning. The substrate influence of this role is attachment styles, which shape experiences and can be internalized and continued by internal working models (Wright, Crawford, \& Castillo, 2009). Therefore, secure attachment style is associated with emotional functions and abilities and insecure attachment style is associated with emotional dysfunctions and inabilities (e.g., Goodall, Trejnowska, \& Darling, 2012). The former condition explains negative association of secure attachment style with alexithymia and the latter one explains positive association of insecure attachment styles with alexithymia.

The results of the present study also revealed that self-regulation had mediating role on the relationship between attachment styles and alexithymia. Regarding that this effect was partial, it can be concluded that association between attachment styles and alexithymia may be due in part to self-regulation. Secure attachment style as the main effective factor in development of impressive emotion regulation skills (Bowlby, 1969; Goodall et al., 2012) provides well identification, expression and better exchange of emotions in social and emotional interactions by reinforcement of self-regulation. In contrast, insecure attachment styles deprive potential developmental opportunities for learning emotion regulation skills within the frame of mother-child and child-environment relations and diminish ability of emotional identification, expression and interactions. This situation provides developmental context of alexithymia (Wearden et al., 2005).

It has been shown that individuals with secure attachment style report lower levels of negative emotions, while individuals with insecure attachment styles experience lower levels of positive emotions and show inability to manage negative emotions (Morley \& Moran, 2011). Positive and negative emotions, which are originated from secure and insecure attachment styles, affect cognitive, motivational-emotional and social processes of self-regulation (Afzal, Malik Najma, \& Atta, 2014; Calkins \& Howse, 2004) hence, creating the intrapsychic basis of emotional abilities or inabilities. These inabilities mainly manifest in deficiencies of understanding, identifying and expressing emotions. Therefore, self-regulation has a mediating role in association between attachment styles and alexithymia. This explanation is supported with the idea that insecure attachment may cause failure in learning how to feel and may pave the way for alexithymia (Wearden et al., 2005).

Neurobiological studies emphasize the role of brain functions on psychological aspects of self-regulation (see Lewis \& Todd, 2007 for a review). The present study focused on the mediating role of self-regulation on the relationship between attachment styles with alexithymia. A more comprehensive understanding of the concept of self-regulation requires interaction of multiple sources and directions, whereby neural components are involved not only in self-regulation but also in attachment styles (e.g., Gillath et al., 2012) and alexithymia (e.g., Bermond et al., 2006). Although the results of the present study are in keeping with our predictions and previous findings, future research can focus on the main and interactive effects of brain systems, attachment styles, and alexithymia.

\subsection{Limitations}

The current study has several limitations. First, the present study was cross-sectional and utilized self-report measures. Although this study provides evidence for the mediating role of self-regulation on the relationship between attachment styles and alexithymia, the cross-sectional design prevents an understanding of the exact nature of the relationships, particularly with respect to directionality. A prospective approach using behavioral 
tasks examining the ability to self-regulate would overcome this shortcoming. There is some evidence that genetic, temperamental, and personality factors influence the development of self-regulation (e.g., Berger, Kofman, Livneh, \& Henik, 2007). The present study did not investigate these variables. This can be considered as the second limitation. This is possible that genetic and personality characteristics may interact with self-regulation to product positive or negative consequences. Future studies need to be pursued to address this issue. Third, the present study focused on only one mediating factor, self-regulation. Consequently, it is important that future studies employ different variables which may have potential to play a mediating role, in order to lead to a better understanding of the role of emotional and cognitive factors in the development and perpetuation of alexithymia. Also for better understanding the disrupting effects of attachment related disorders on emotional processes, it is suggested to study this relationship in clinical samples including individuals with psychological disorders, personality disorders and samples with familial and interpersonal problems.

\subsection{Implications}

Nonetheless, the present study may have important implications. Results of this study provide further support for attachment theory assumptions about the role of internal working models of attachment on emotion regulation. From this point of view, emotion regulation mechanisms are not considered just as intrapsychic and personal phenomena, but also it emphasizes on the role of interpersonal variables from child-mother (caregiver) relationship to further social relations. In addition, confirmation of mediating effect of self-regulation on the relationship between attachment styles and alexithymia can be useful for coherency and integrity of attachment and personality theories assumptions. Furthermore, findings of this study can be an appropriate empirical basis to develop health and education programs in the frame of mother-child relationships, emotion management interventions and interpersonal-based therapies whether in client-client relation (like couples) or client-therapist relations. Clinicians should consider working with clients to reduce their insecure characteristics. These efforts might involve attempts to identify and alter emotional dysregulations, difficulties of identifying and describing feelings, and problems with expression of emotions as well as self-regulating strategies in order to increase emotional functioning. These programs might also help the existing attachment based and emotional oriented intervention models.

\section{Acknowledgments}

The authors would like to acknowledge the financial support of University of Tehran for this research under grant number 5106003/1/59.

\section{References:}

Afzal, A., Malik Najma, I, \& Atta, Mohsin (2014). The moderating role of positive and negative emotions in relationship between positive psychological capital and subjective well-being among adolescents. International Journal of Research Studies in Psychology, 3(3), 29-42. http://dx.doi.org/10.5861/ijrsp.2014.687

Bagby, R. M., Parker, J. D. A., \& Taylor, G. J. (1994). The twenty-item Toronto Alexithymia Scale: Item selection and cross-validation of the factor structure. Journal of Psychosomatic Research, 38, 23-32. http://dx.doi.org/10.1016/0022-3999(94)90005-1

Bartholomew, K., \& Horowitz, L. (1991). Attachment styles among young adults: a test of a four-category model. Journal of Personality and Social Psychology, 61, 226-244. http://dx.doi.org/10.1037/0022-3514.61.2.226

Berger, A., Kofman, O., Livneh, U., \& Henik, A. (2007). Multidisciplinary perspectives on attention and the development of self-regulation. Progress in Neurobiology, 82, 256-286. 
The relationship between attachment styles and alexithymia: Mediating role of self-regulation

http://dx.doi.org/10.1016/j.pneurobio.2007.06.004

Bermond, B., Vorst, H. C. M., \& Moormann, P. P. (2006). Cognitive neuropsychology of alexithymia: Implications for personality typology. Cognitive Neuropsychiatry, 11, 332-360. http://dx.doi.org/10.1080/13546800500368607

Besharat, M. A. (2007). Reliability and factorial validity of Farsi version of the Toronto Alexithymia Scale with a sample of Iranian students. Psychological Reports, 101, 209-220.

Besharat, M. A. (2010). Attachment styles and alexithymia. Psychological Research, 24, 63-80. [Farsi]

Besharat, M. A. (2005) Development and validation of the Adult Attachment Inventory. Unpublished research report. Tehran: University of Tehran. [Farsi]

Besharat, M. A. (2011). Psychometric properties of a short version of the Self-Regulation Inventory in a sample of Iranian population. Research in Clinical Psychology and Counseling, 2, 53-70. [Farsi]

Bowlby, J. (1969). Attachment and loss: Vol. I. Attachment. New York: Basic Books.

Bowlby, J. (1988). A secure base: clinical applications of attachment theory. New York: Basic Books.

Calkins, S. D., \& Howse, R. B. (2004). Individual differences in self-regulation: Implications for childhood adjustment. In P. Philippot \& R. S. Feldman (Eds.), The regulation of emotion (pp. 307-332). Mahwah, NJ: Lawrence Erlbaum Associates, Publishers.

Crowell, J. A., Fraley, R. C., \& Shaver, P. R. (1999). Measurement of individual differences in adolescents and adult attachment. In J. Cassidy \& P. R. Shaver (Eds.), Handbook of Attachment: Theory, research, and clinical applications (pp. 434-465). New York, US: Guilford Press.

Dewitte, M., Houwer, J. D., Goubert, L., \& Buysse, A. (2010). A multi-modal approach to the study of attachment-related distress. Biological Psychology, 85, 149-162. http://dx.doi.org/10.1016/j.biopsycho.2010.06.006

Dorris, D. C. (2009). Self-regulation and the hypothesis of experience-based selection: Investigating indirect conscious control. Consciousness and Cognition, 18, 740-753. http://dx.doi.org/10.1016/j.concog.2009.03.005

Frawley, W., \& Smith, R. N. (2001). A processing theory of alexithymia. Cognitive Systems Research, 2, $189-206$. http://dx.doi.org/10.1016/S1389-0417(01)00029-8

Gergely, G., \& Watson, J. S. (1996). The social biofeedback theory of parental affect-mirroring: the development of emotional self-awareness and self-control in infancy. International Journal of Psychoanalysis, 77, $1-31$.

Gillath, O., Canterberry, M., \& Collins, T. J. (2012). A multilevel, multimethod interdisciplinary approach to the understanding of attachment. In: O. Gillath, G. Adams, \& A. Kunkel (Eds.), Relationship science: Integrating evolutionary, neuroscience, and sociocultural approaches (pp. 219-240). Washington, DC: American Psychological Association.

Goodall, K., Trejnowska, A., \& Darling, D. (2012). The relationship between dispositional mindfulness, attachment security and emotion regulation. Personality and Individual Differences, 52, 622-626. http://dx.doi.org/10.1016/j.paid.2011.12.008

Hanif, A., Ferrey, A. E., Frischen, A., Pozzobon, K., Eastwood, J. D., Smilek, D., et al. (2012). Manipulations of attention enhance self-regulation. Acta Psychologica, 139, 104-110. http://dx.doi.org/10.1016/j.actpsy.2011.09.010

Hazan, C., \& Shaver, P. R. (1987). Romantic love conceptualized as an attachment process. Journal of Personality and Social Psychology, 52, 511-524. http://dx.doi.org/10.1037/0022-3514.52.3.511

Hershenberg, R., Davila, J., Yoneda, A., Starr, L. R., Miller, M. R., Stroud, C. B., et al. (2011). What I like about you: The association between adolescent attachment security and emotional behavior in a relationship promoting context. Journal of Adolescence, 34, 1017-1024.

http://dx.doi.org/10.1016/j.adolescence.2010.11.006

Ibáñez, M. I., Ruipérez, M. A., Moya, J., Marqués, M. J., \& Ortet, G. (2005). A Short version of the Self-Regulation Inventory (SRI-S). Personality and Individual Differences, 39, 1055-1059. http://dx.doi.org/10.1016/j.paid.2005.02.029

Calkins, S. D., \& Howse, R. B. (2004). Individual differences in self-regulation: Implications for childhood 
adjustment. In P. Philippot \& R. S. Feldman (Eds.), The regulation of emotion (pp. 307-332). Mahwah, NJ: Lawrence Erlbaum Associates, Publishers.

Karukivi, M., Joukamaa, M., Hautala, L., Kaleva, O., Haapasalo-Pesu, K. M., Liuksila, P. R., et al. (2011). Does perceived social support and parental attitude relate to alexithymia? A study in Finnish late adolescents. Psychiatry Research, 187, 254-260. http://dx.doi.org/10.1016/j.psychres.2010.11.028

Kreitler, S. (2002). The psychosemantic approach to alexithymia. Personality and Individual Differences, 33, 393-407. http://dx.doi.org/10.1016/S0191-8869(01)00163-5

Lewis, M. D., \& Todd, R. M. (2007). The self-regulating brain: Cortical-subcortical feedback and the development of intelligent action. Cognitive Development, 22, 406-430. http://dx.doi.org/10.1016/j.cogdev.2007.08.004

Lowe, J. R., Maclean, P. C., Duncan, A. F., Aragón, C., Schrader, R. M., Caprihan, A., \& Phillips, J. P. (2012). Association of maternal interaction with emotional regulation in 4- and 9-month infants during the Still Face Paradigm. Infant Behavior and Development, 35, 295-302. http://dx.doi.org/10.1016/j.infbeh.2011.12.002

Marques, M. J., Ibanez, M. I., Ruiperez, M. A., Moya, J., \& Ortet, G. (2005). The Self-Regulation Inventory (SRI): Psychometric properties of a health related coping measure. Personality and Individual Differences, 39, 1043-1054. http://dx.doi.org/10.1016/j.paid.2005.02.030

Morley, T. E., \& Moran, G. (2011). The origins of cognitive vulnerability in early childhood: Mechanisms linking early attachment to later depression Review Article. Clinical Psychology Review, 31, 1071-1082. http://dx.doi.org/10.1016/j.cpr.2011.06.006

Roque, L., \& Veríssimo, M. (2011). Emotional context, maternal behavior and emotion regulation. Infant Behavior and Development, 34, 617-626. http://dx.doi.org/10.1016/j.infbeh.2011.06.002

Sifneos, P. E. (2000). Alexithymia, clinical issues, politics and crime. Psychotherapy and Psychosomatics, 69, 113-116. http://dx.doi.org/10.1159/000012377

Thorberg, F. A., Young, R. M., Sullivan, K. A., Lyvers, M., Connor, J. P., \& Feeney, G. F. X. (2010). A psychometric comparison of the Toronto Alexithymia Scale (TAS-20) and the Observer Alexithymia Scale (OAS) in an alcohol-dependent sample. Personality and Individual Differences, 49, 119-123. http://dx.doi.org/10.1016/j.paid.2010.03.018

Vallotton, C., \& Ayoub, C. (2011). Use your words: The role of language in the development of toddlers' self-regulation. Early Childhood Research Quarterly, 26, 169-181. http://dx.doi.org/10.1016/j.ecresq.2010.09.002

Wearden, A. J., Lamberton, N., Crook, N., \& Walsh, V. (2005). Adult attachment, alexithymia, and symptom reporting: An extension to the four category model of attachment. Journal of Psychosomatic Research, 58, 279-288. http://dx.doi.org/10.1016/j.jpsychores.2004.09.010

Wright, M. O., Crawford, E., \& Castillo, D. D. (2009). Childhood emotional maltreatment and later psychological distress among college students: The mediating role of maladaptive schemas. Child Abuse \& Neglect, 33, 59-68. http://dx.doi.org/10.1016/j.chiabu.2008.12.007 